\title{
INTEGRATED WELLINGTON REGION LAND TRANSPORT RESILIENCE STUDY
}

\author{
Pathmanathan Brabhaharan ${ }^{1}$
}

(Submitted November 2020; Reviewed December 2020; Accepted April 2021)

\begin{abstract}
Wellington region's transport network has poor resilience to natural hazards, given the rugged terrain, high seismicity and wet climate. This exposes the land access to the region and the capital city to be potentially cut off from the rest of New Zealand for several months, and its cities to be isolated from each other.

This paper reports on a pioneering integrated resilience study of the entire land transport system in the region provided by the state highways, principal and arterial local roads and the railway system. The study considered resilience risks from a range of natural hazards (earthquake, storm and tsunami) using the metrics of availability and outage. The resilience risks and the relative importance of the routes were used to assess the criticality of these risks for future investment in resilience enhancement. The criticality also considered risks to other lifeline utilities - power, water and telecommunications that share these transport corridors. The combined criticality was used to prioritise these resilience risks. The highest criticality resilience risks were classified into extreme, very high and high levels. The extreme criticality risks identified were the state highway between Ngauranga and Petone and the adjacent Ngauranga interchange between the two State Highways 1 and 2, which together provide access between Wellington, Hutt and Porirua cities. A range of very high risks were identified across the region which included both state highways and local roads. This novel resilience study provided the basis for a subsequent business case for future investment to enhance the resilience of the region's transport network.
\end{abstract}

\section{INTRODUCTION}

A combination of high seismicity, rugged terrain, coastal environment and weather conditions make Wellington's land transport system to be highly vulnerable to natural hazards, particularly earthquakes, storms and tsunami events, see aerial view of Wellington City in Figure 1. Active faults in the region are shown on the map in the Appendix.

Over the past 30 years, Wellington has led the way with understanding the resilience of its lifeline infrastructure, starting with the first lifelines study in New Zealand in 19901991 led by the Centre for Advanced Engineering [1] and

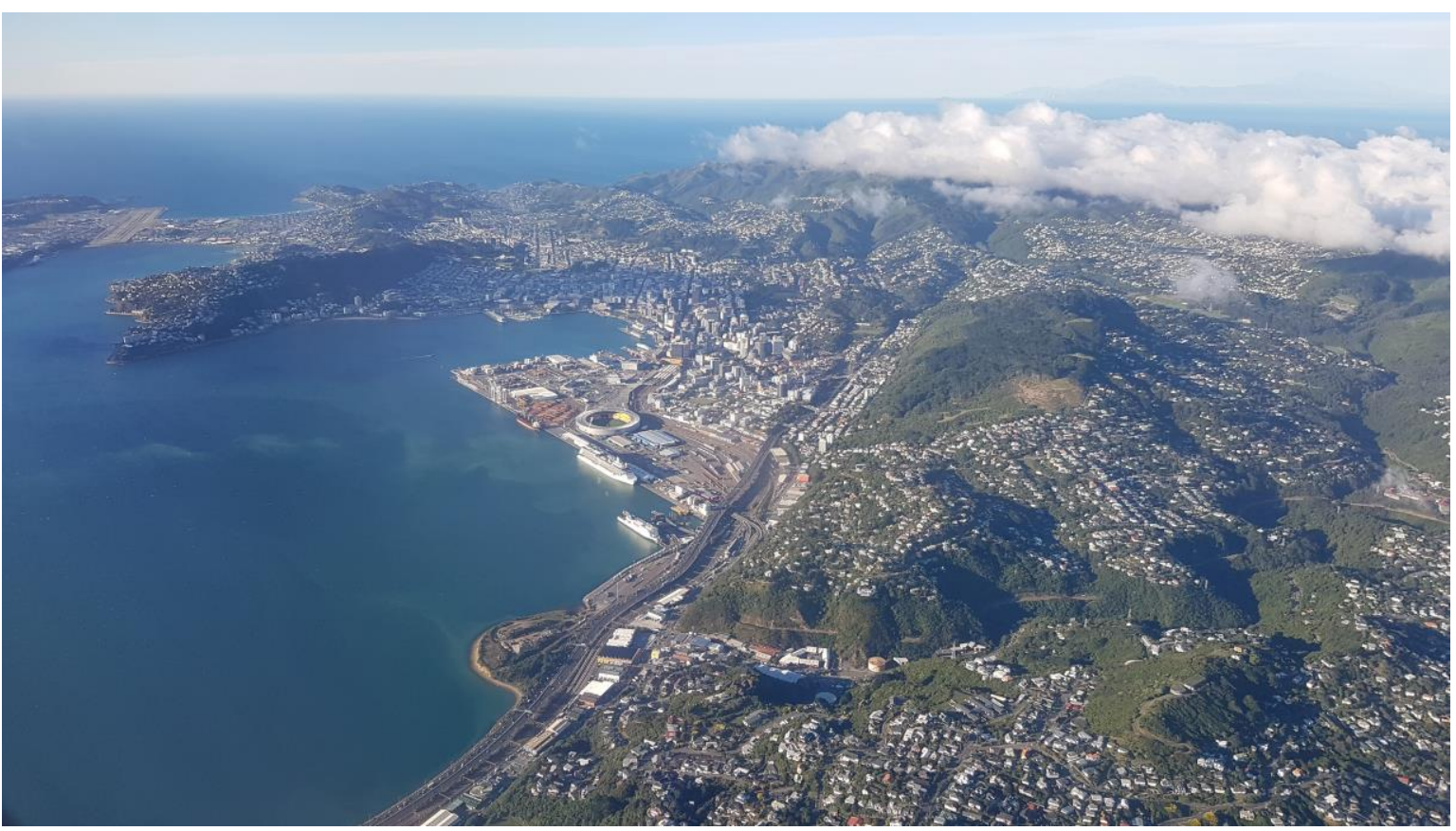

Figure 1: View of Wellington city showing the terrain (see Appendix for active faults in the region). 
studies focusing on the resilience of its transport system [2-6]. Similar lifelines studies have followed for other regions, for example Canterbury [7], and road resilience studies for other regions, for example Western Bay of Plenty [8].

A systematic characterisation of the earthquake resilience of Wellington city's road network was first completed in 2002 [9] with the aid of a geospatial platform and was enhanced over the following years in parallel with research into road network resilience risk management [10-12]. This work enabled Wellington City Council to implement a long-term programme of strengthening its road infrastructure. This programme has been implemented over the past 20 years [13-14] and is ongoing. Similar assessments and mapping of the resilience of the adjacent cities of Upper Hutt, Hutt City [3], Porirua [4] and the state highways [5] were carried out over the next decade.

The state highways and local authority road networks operate as a combined road network to provide access. Appreciating this, a joint integrated resilience study was initiated, and updated and brought the earthquake resilience of the entire road network together for the state highways, and the local authority networks in Wellington City, Hutt City, Upper Hutt City, Porirua City and Kapiti Coast District, reported by Brabhaharan and Mason [6,15], see Figure 2. The spatial resilience data for the different networks were held separately so that relevant road controlling authorities retain ownership for maintenance and updating. The data was spatially meshed together for common use in understanding the resilience of the regional network.

A strategic business case for transport resilience in the region was developed in 2016 [16] and highlighted the key resilience issues affecting the Wellington region identified by the 2012 study [6], benefits of investments in enhancing resilience, and the objectives of the business case for resilience, which led to the investment logic map presented in Figure 3. This provided the basis for the prioritisation of resilience risks described in this paper and the subsequent development of a programme business case for resilience. This paper describes the transport resilience risks in the region, assessment of their criticality of these risks, and its use for prioritisation for investment. Development of the investment programme is not covered in this paper and will be addressed in the future.

\section{STRUCTURE OF PROGRAMME BUSINESS CASE}

The need for a more detailed business case to understand and prioritise the transport resilience risks and develop resilience enhancement measures for the region's entire land transport system led to the development of a programme business case for land transport resilience for the Wellington region. The objective of the business case was to improve access, reduce closure times and the isolation of the region, and thus reduce socio-economic impacts of large natural hazards, see Figure 3.

The study was carried out in three stages:

1) Stage 1 - Identification of gaps in available resilience data, additional assessment to supplement and enhance the resilience data, development of methodology, prioritisation of resilience risks and compilation of a resilience risk register and maps.

2) Stage 2 - Analyses to identify remaining risks considering transport initiatives already underway, but not completed.

3) Stage 3 - Development of resilience interventions to address the resilience risks, followed by the formulation and comparison of different programs, leading to the identification of a preferred resilience enhancement programme, and management case.

The study included workshops with key stakeholders at regular intervals to seek feedback and comments and obtain buy-in to the resilience risks identified and the resilience interventions proposed as the study progressed, as outline later in this paper. Stages 2 and 3 are not included in this paper.

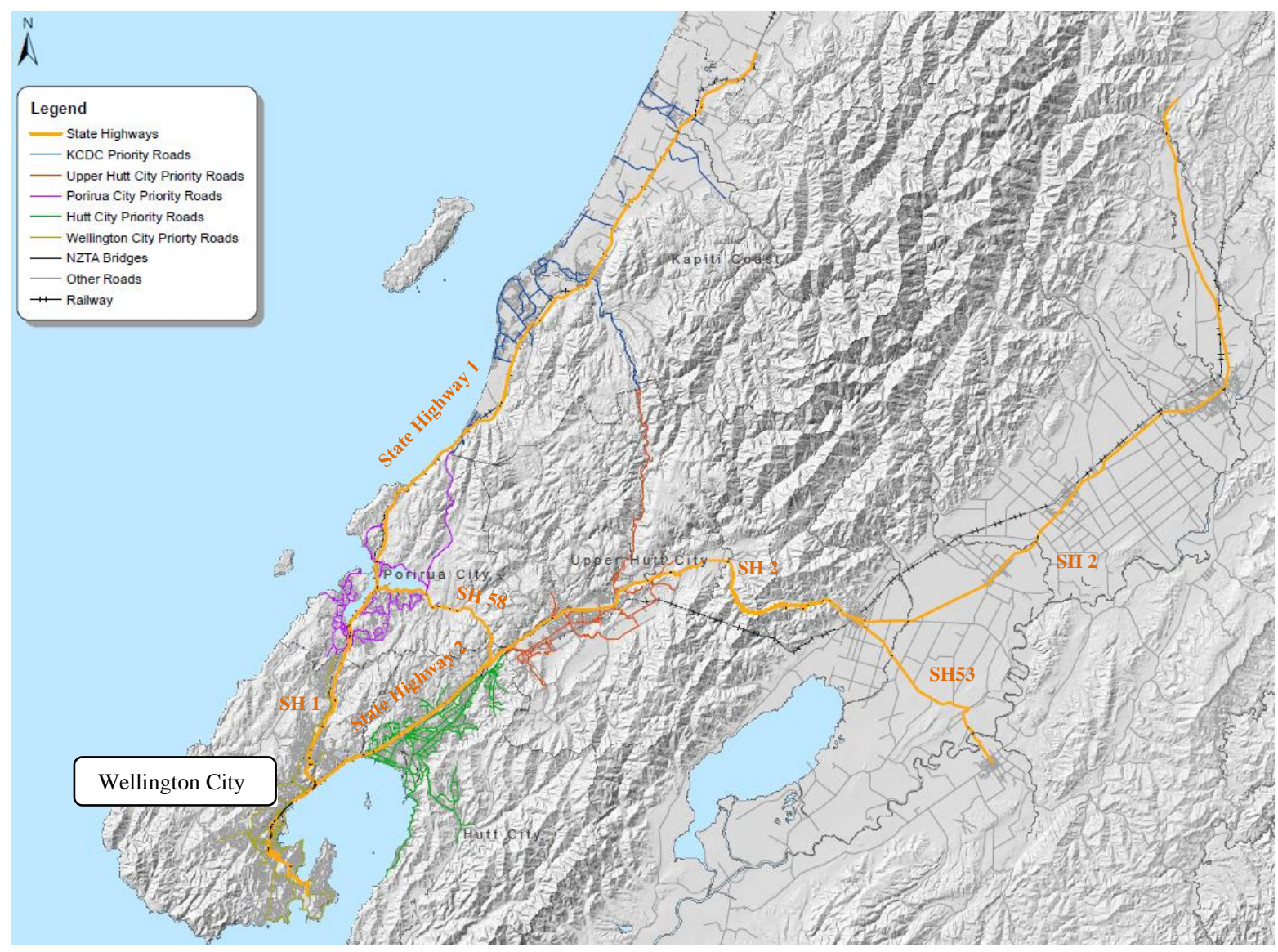

Figure 2: Transport network in the Wellington region comprising state highways and important local roads. 


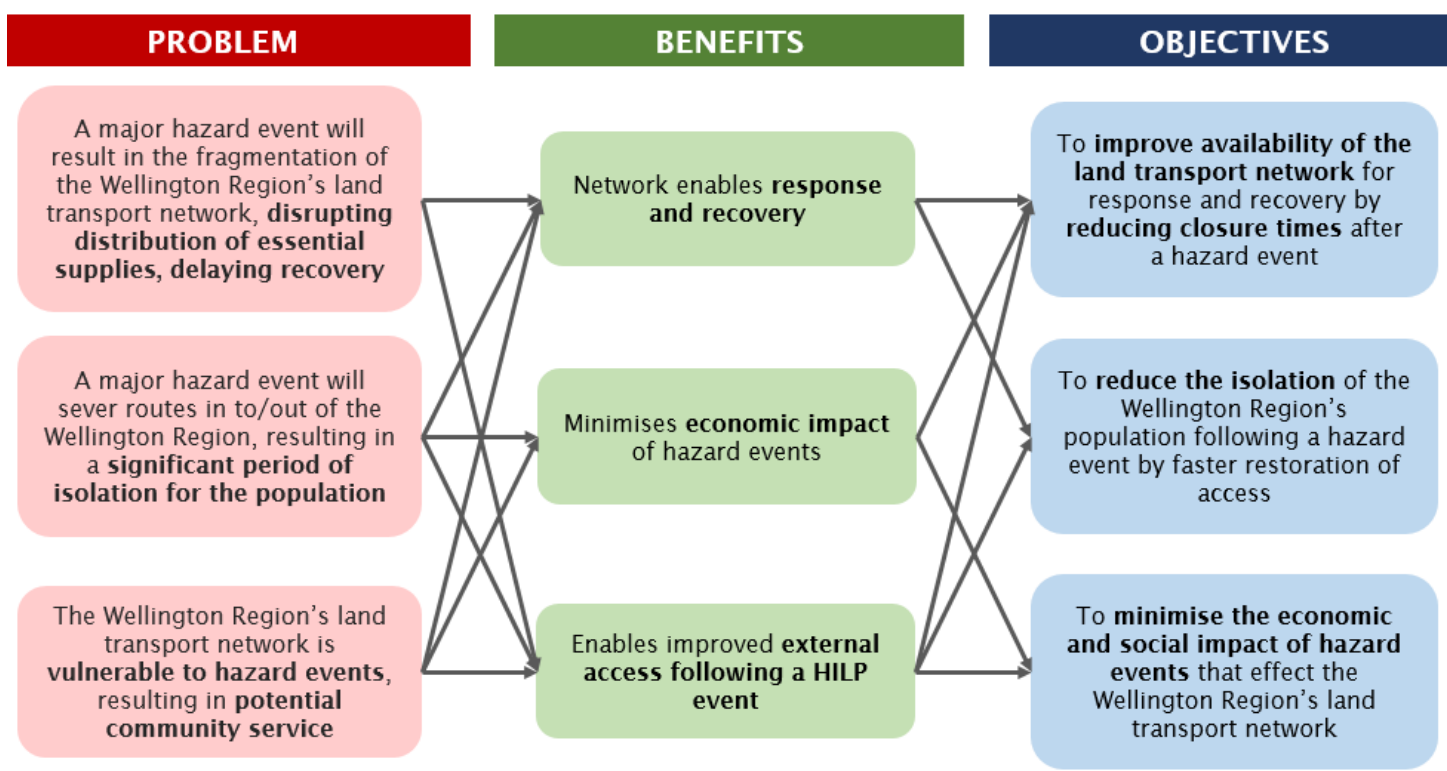

Figure 3: Investment logic map for land transport resilience.

\section{STAGE 1 - PRIORITISATION OF RESILIENCE RISKS}

Stage 1 of the study involved collating the resilience risks from prior studies, with supplementary assessment as necessary, followed by prioritisation of the resilience risks.

\section{Resilience to Earthquakes}

The 2012 road network resilience study [6] provided a robust basis for understanding the resilience of the land transport system. This study provided the resilience of the system to large local earthquakes of Richter magnitude 7.5. It is noted that the resilience of the railway network had not been assessed in a similar manner as part of the 2012 study which focussed on the road transport system.

The resilience of the transport network was characterised using the resilience concepts proposed by Brabhaharan [9], shown diagrammatically on Figure 4.

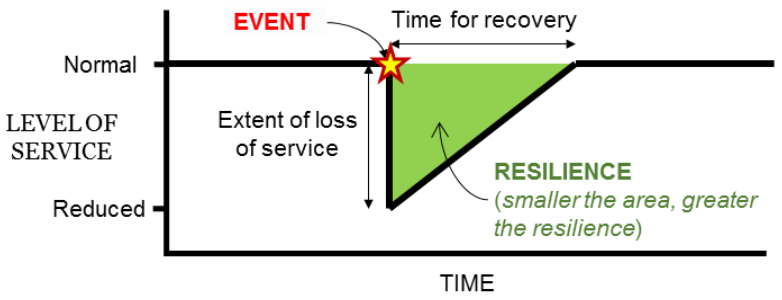

Figure 4: Concept of resilience for transport routes.

Two metrics developed and used to assess resilience, which are consistent with this concept were:

- Availability state - level of access available after an event

- Outage state - duration of impaired access

The metrics of availability and outage developed to characterise the resilience of the road networks $[12,13]$ is presented in Figure 5.

The resilience of the Wellington transport network to a large magnitude 7.5 local earthquake in the region using the availability and outage state metrics is shown on Figures 6 and 7 respectively. The assessments take into consideration the ground shaking from the earthquakes as well as consequential hazards of earthquake induced landslides [17], liquefaction and associated subsidence and lateral spreading $[18,19]$.

\begin{tabular}{|c|c|c|}
\hline \multicolumn{3}{|r|}{ Availability State } \\
\hline Level & State & Description \\
\hline 1 & Full & Full access except condition may require care. \\
\hline 2 & Poor & $\begin{array}{l}\text { Available for slow access, but with difficulty by } \\
\text { normal vehicles due to partial lane blockage, } \\
\text { erosion or deformation. }\end{array}$ \\
\hline 3 & Single lane & $\begin{array}{l}\text { Single lane access only with difficulty due to } \\
\text { poor condition of remaining road. }\end{array}$ \\
\hline 4 & Difficult & $\begin{array}{l}\text { Road accessible single lane by only } 4 \times 4 \text { off road } \\
\text { vehicles. }\end{array}$ \\
\hline 5 & Closed & Road closed and unavailable for use. \\
\hline
\end{tabular}

\begin{tabular}{|c|c|l|}
\hline \multicolumn{3}{|c|}{ Outage State } \\
\hline Level & State & \multicolumn{1}{|c|}{ Description } \\
\hline 1 & Open & No closure, except for maintenance \\
\hline 2 & Minor & Condition persists for up to 1 day \\
\hline 3 & Moderate & Condition persists for 1 day to 3 days \\
\hline 4 & Short term & Condition persists for 3 days to 2 weeks \\
\hline 5 & Medium term & Condition persists for 2 weeks to 2 months \\
\hline 6 & Long term & Condition persists for 2 months to 6 months \\
\hline 7 & $\begin{array}{c}\text { Very long } \\
\text { term }\end{array}$ & Condition persists for greater than 6 months \\
\hline
\end{tabular}

Figure 5: Resilience metrics - Availability and Outage States (after Brabhaharan [13]).

A description of the detailed methodology used for the derivation of the resilience states using a spatial approach is presented in the previous reports and papers [3-6].

The maps indicate that a major earthquake will close State Highways 1 and 2 and alternate local routes, and disrupt access for essential supplies, delay recovery and lead to isolation of the population for a significant period, as noted in Figure 3. 


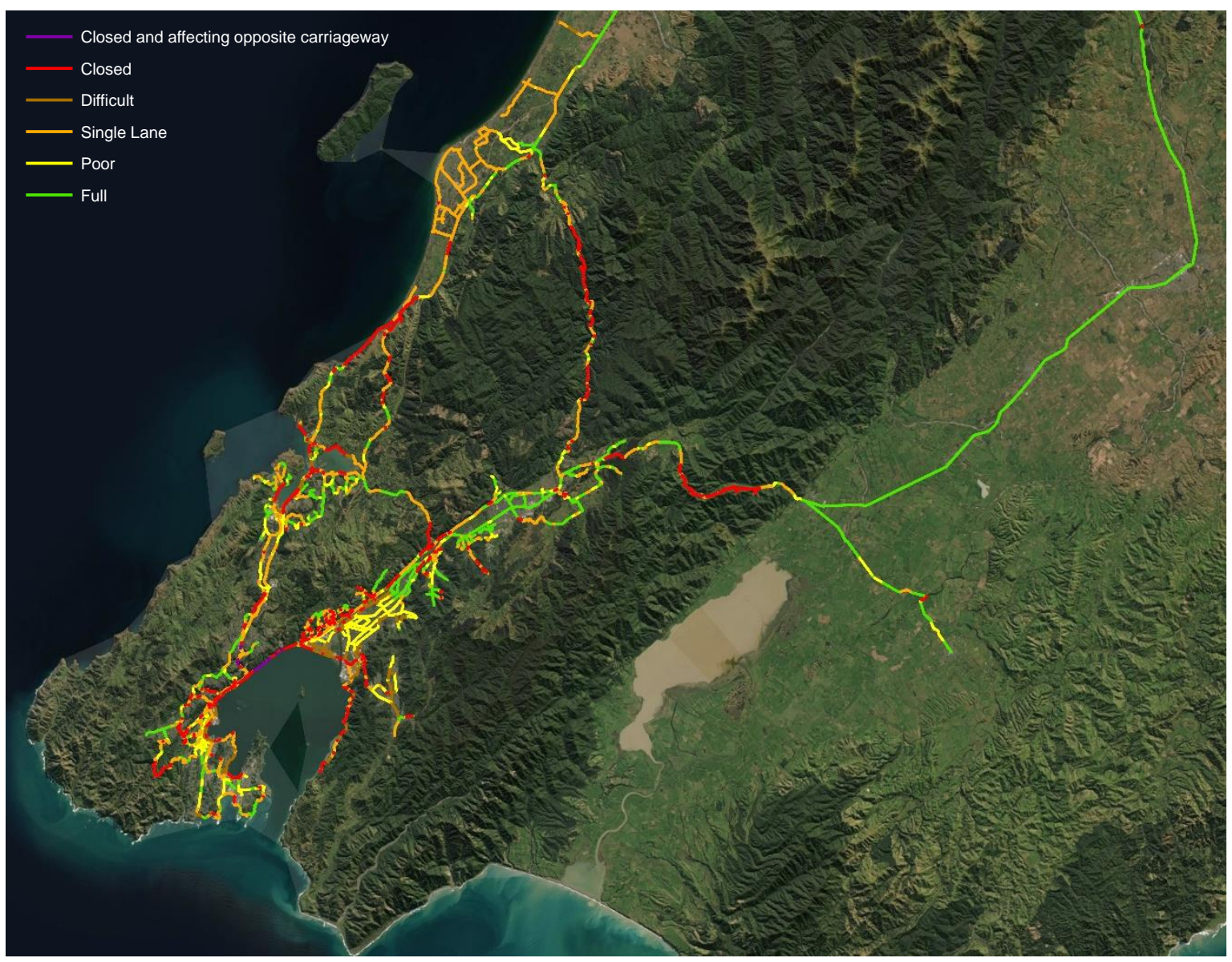

Figure 6: Availability of transport network after a large magnitude 7.5 local earthquake.

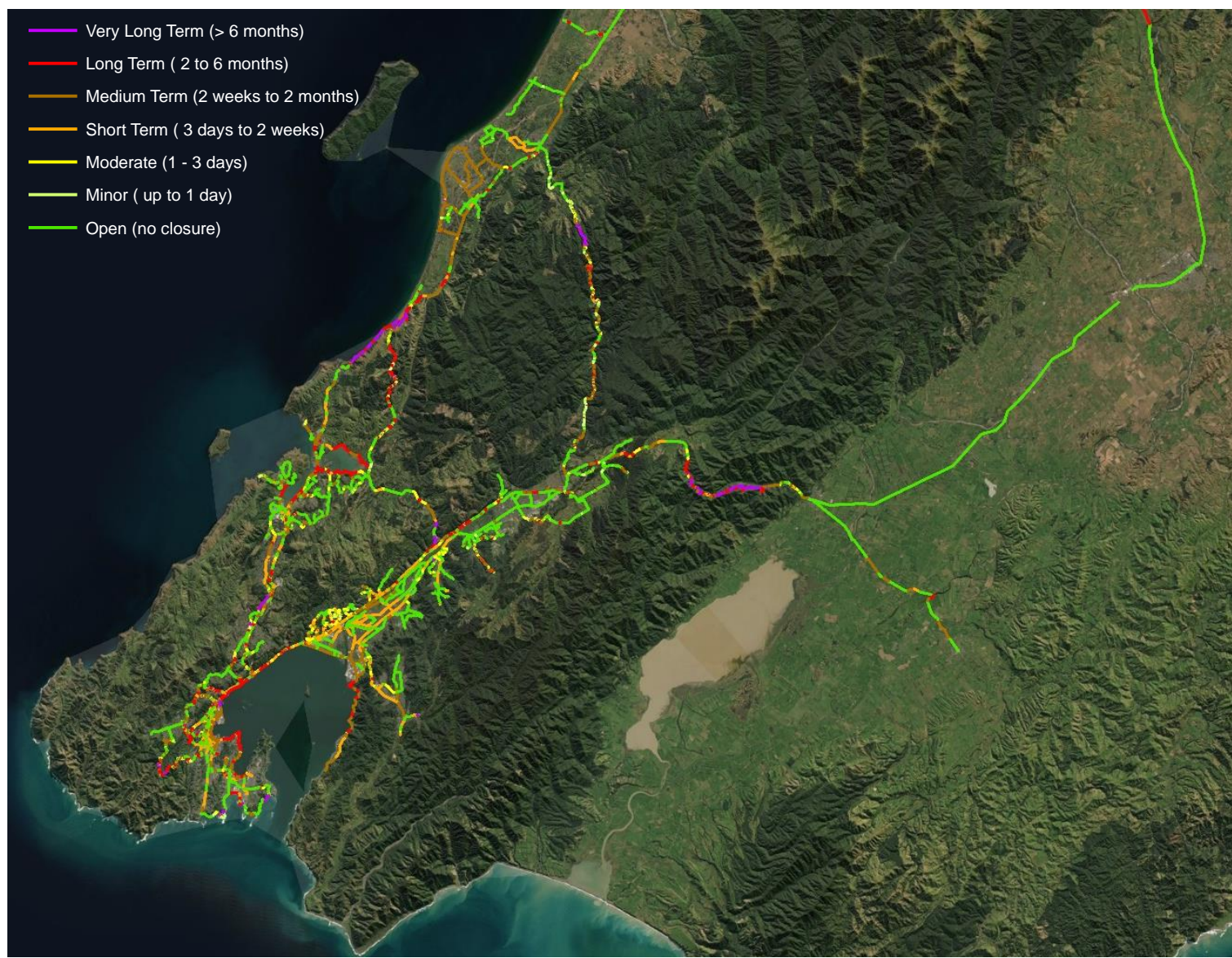

Figure 7: Outage of transport network after a large magnitude 7.5 local earthquake, characterised using the resilience metrics in Figure 5. 


\section{Resilience to Large Storm Events}

Though resilience assessments were available for large earthquakes, assessment of the resilience in storm hazards was only available for Lower Hutt [3] and a limited corridor along the state highway system.

Additional work was carried out to assess the resilience of the transport network to a large 100-year return period storm event as part of this study, using a similar spatial approach and the characterisation of the transport networks already carried out as part of the previous studies [3-6]. The storm event resilience also captures the related hazards - landslides, flooding, coastal erosion and storm surge caused by the storm events.
The availability state after such a storm event is shown on Figure 8 , which indicates that the population centres and cities in the region are likely to be cut off.

The closure in storm events will be for periods of some to many weeks for some routes and for longer periods for some routes, see outage state map in Figure 9, which is shorter than the outage expected after a large earthquake.

These assessments highlight the vulnerability of the existing land transport networks to natural hazards, and the importance of the resilience business case so that there is a coherent and coordinated strategy to enhance resilience of land transport access in the region over time.

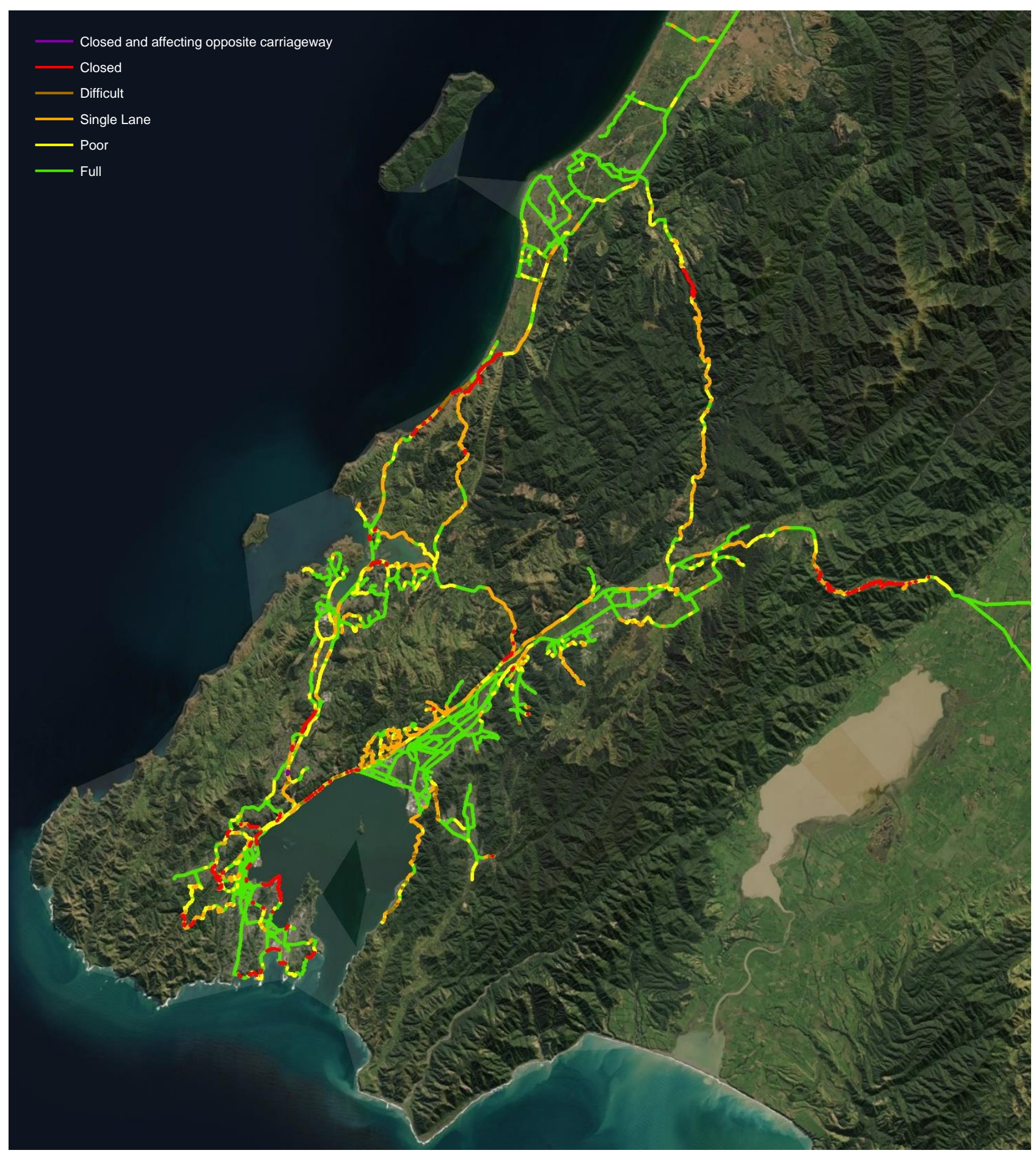

Figure 8: Availability of transport links after a large storm. 


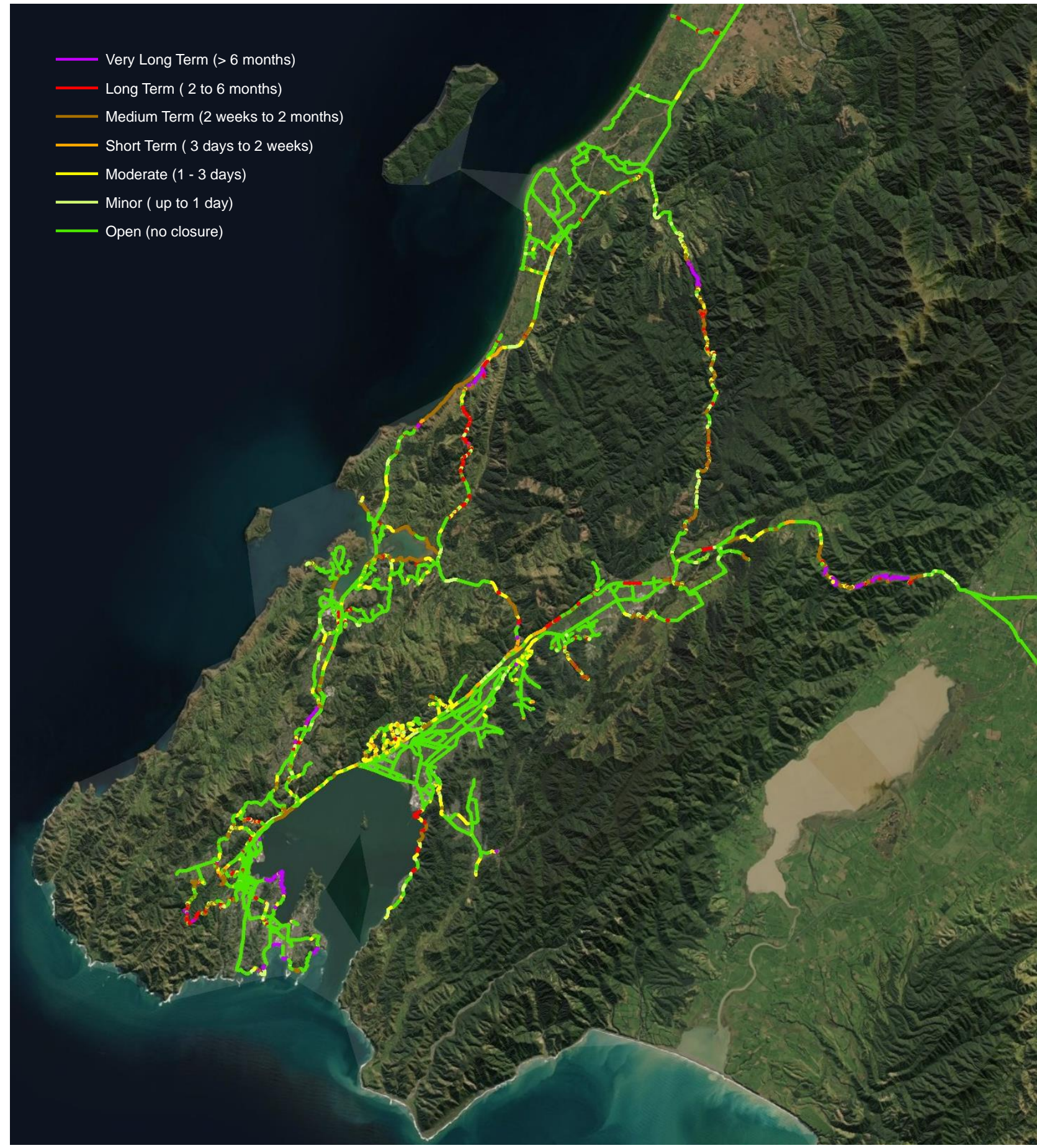

Figure 9: Outage of transport links after a large storm event.

\section{Disruption State}

The resilience metrics of availability state and outage state were combined into a single metric known as disruption state using the approach developed as part of previous research [12]. A description of the resilience metrics of availability state and outage state, and the combination into a single metric of disruption state is shown in Figure 10.

The disruption state metric is less meaningful than the availability and outage state metrics, because the availability in terms of access and outage representing the period of impaired access, are metrics that have physical meanings and can be understood by asset managers, stakeholders and the public. Nevertheless, disruption state was derived as a single metric mainly for use in the prioritisation of the resilience risks as discussed later in this paper.
The disruption state for the Wellington transport system was derived from the availability and outage states. The disruption state in a large local magnitude 7.5 earthquake is presented in Figure 11.

The map shows that sections of the transport system that are likely to be closed and have an outage period of more than 6 months have disruption states classified as catastrophic. This is because access will be completely cut off for a long period of time, leading to isolation.

Unfortunately, the key transport routes in and out of the greater Wellington area (State Highways 1 and 2) as well as the between the cities have extreme to catastrophic disruption states (highlighted on Figure 11), and therefore the resilience risks are critical for the Wellington region. 


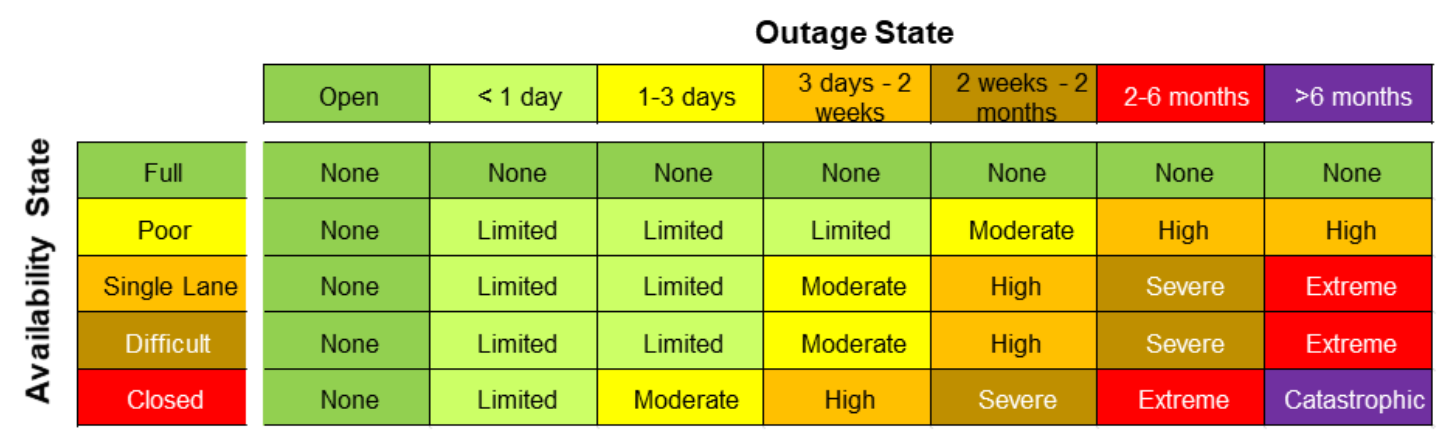

Figure 10: Disruption state from availability and outage.

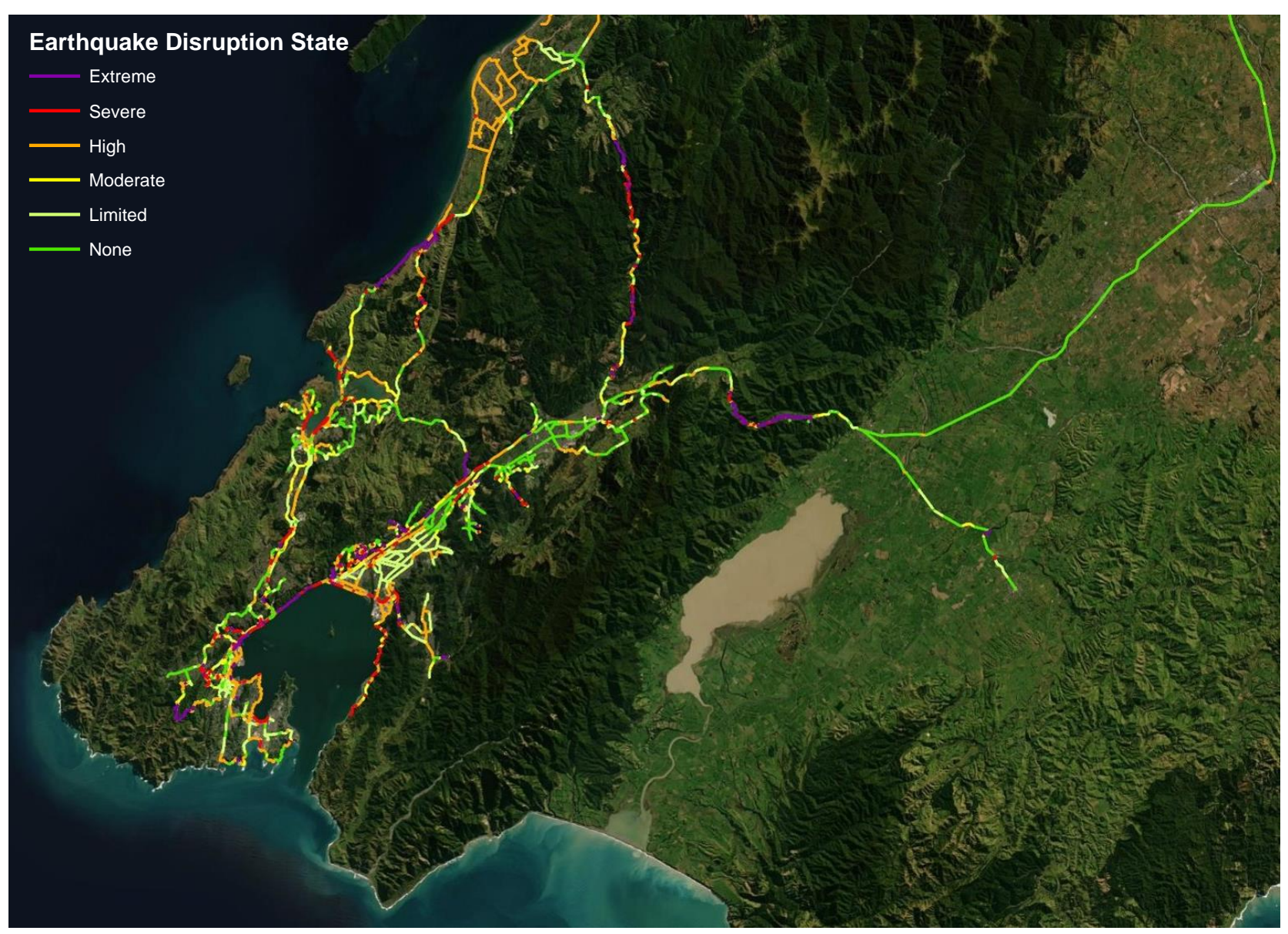

Figure 11: Disruption state of transport links after a large magnitude 7.5 local earthquake, derived from availability and outage metrics using the approach shown in Figure 10.

\section{Transport Resilience Impacts from Buildings}

A key observation from the 2010-2011 Canterbury earthquake sequence which reinforced overseas observations during reconnaissance after the Wenchuan earthquake in China in 2008 [20], was that access along inner-city transport routes were closed due to damage or collapse of buildings and safety hazards posed by buildings damaged by the earthquakes and aftershocks, even where the roads themselves were not damaged.

Considering this observation, the post-earthquake availability state of inner-city roads in Wellington City was assessed considering the type and height of buildings along the routes, and the likely impact on accessibility considering potential building collapse, damage and safety hazards for road users. Higher and more vulnerable building topologies could cause more disruption due to damage or safety concerns.
The expected availability state of the inner-city transport routes in the Wellington central business district (CBD) is shown on Figure 12. This assessment shows that although the roads in the flat inner-city areas themselves are unlikely to be significantly damaged by the earthquake sufficiently to cause closure, they could still be closed due to earthquake damage to adjacent buildings.

The following parameters of buildings were considered in assessing whether the transport routes are likely to be affected or closed by building damage and associated safety concerns:

- Heights of buildings and estimated number of storeys

- Unreinforced masonry (URM) buildings

- Earthquake prone buildings

The heights of buildings were estimated from available GIS information, and earthquake prone buildings and URM 
buildings from published data and are indicated in the map for the Wellington CBD and surrounding area shown in Figure 12.

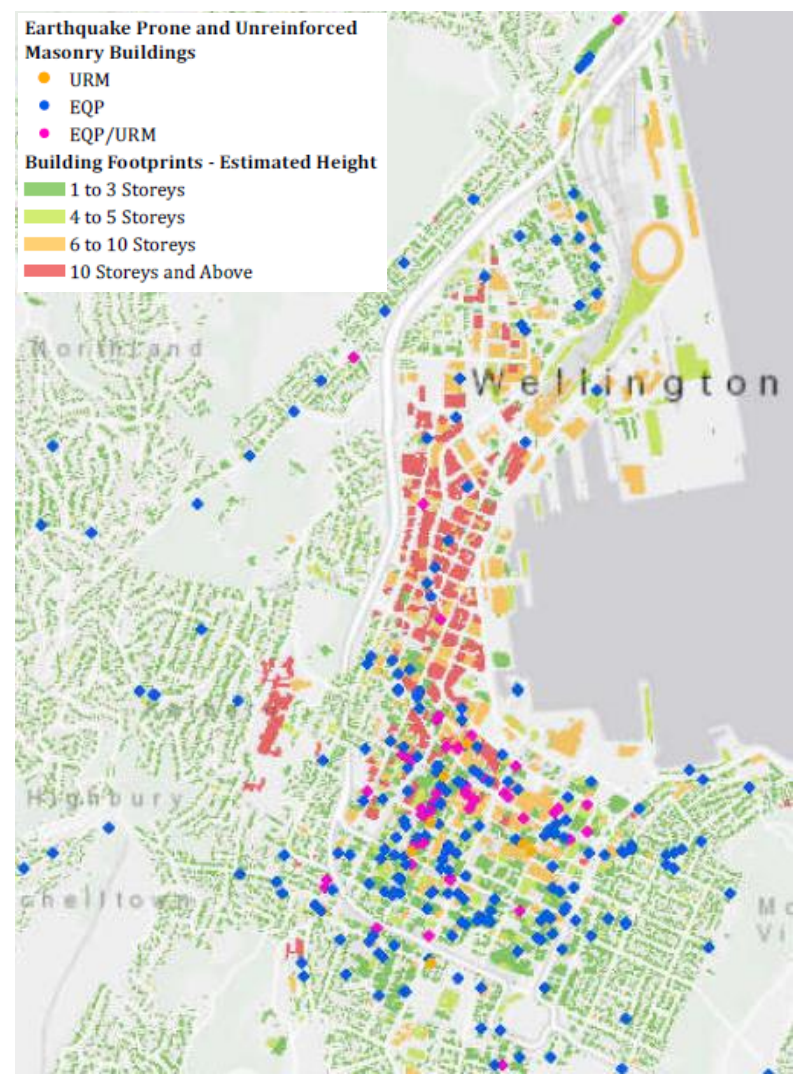

Figure 12: Characteristics of buildings along transport routes in the CBD of Wellington City.

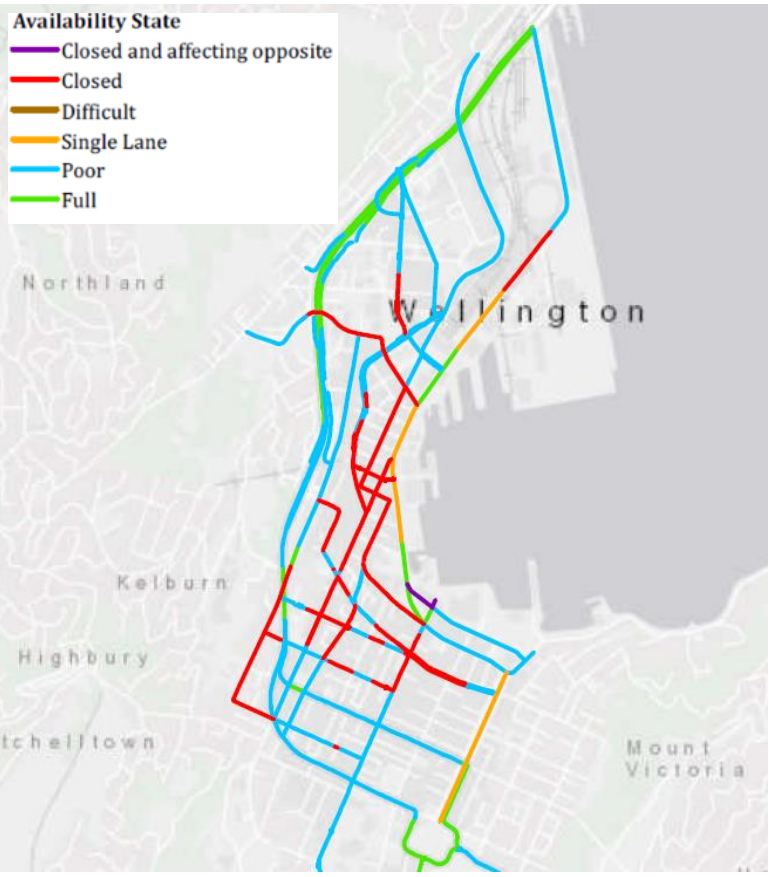

Figure 13: Resilience impact from potential building damage along transport routes in the Wellington CBD.

It was assumed that buildings could affect about 1.5 times its height from the base of the building (Jason Ingham - personal communication). Given the generally narrow roads in the CBD, this assumption wasn't particularly important. The areas of influence of buildings was assessed based on their heights using GIS. The likely closure of routes was based on these parameters and observations during the 2010-2011 Canterbury Earthquake Sequence and overseas observations [20].

Figure 13 shows that many of the inner-city streets of Wellington are likely to be closed due to building hazards, and together with damage to the harbour quays due to liquefaction and lateral spreading, will restrict access across the city after a significant large earthquake.

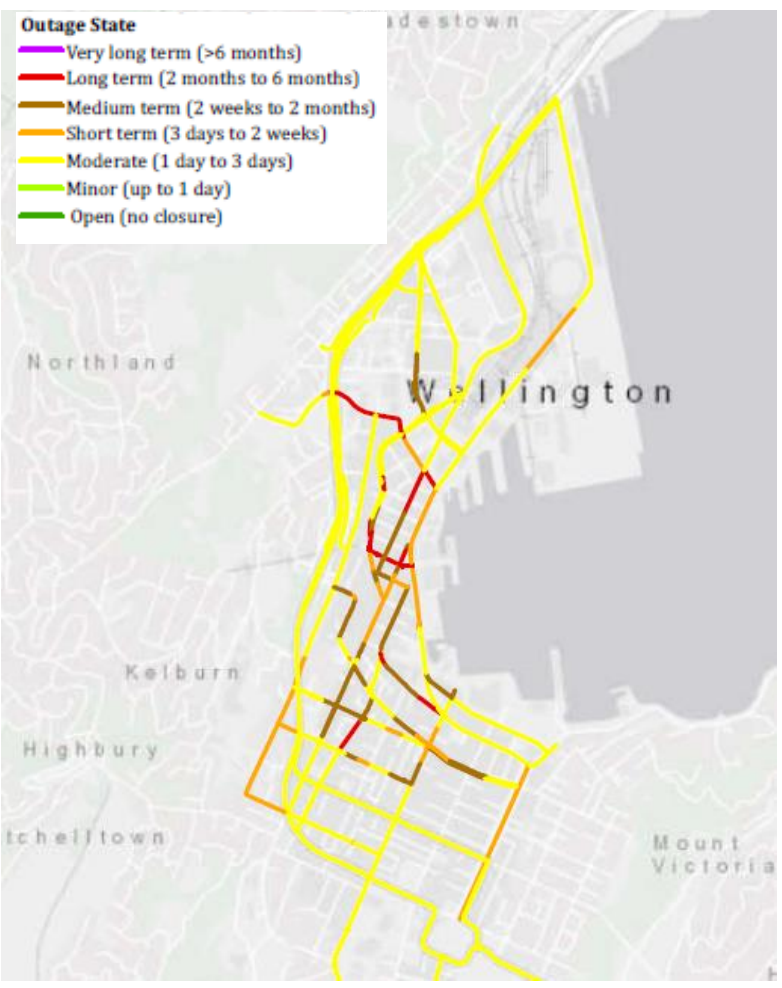

Figure 14: Possible outage period from potential building damage along transport routes in the Wellington $C B D$.

A possible outage state indicating the period of closure is shown on Figure 14. Note that these assessments are indicative and will depend on many factors including the characteristics of the earthquake. The purpose of the assessment is to consider whether the inner-city streets would be available for access in the aftermath of a large earthquake. The assessment indicates that the inner-city streets wouldn't be available for access for weeks and possibly months, and therefore the resilience of the state highway would be critical for access across the city. This highlights the importance of the resilience of the state highway route around the CBD given that the inner-city streets are likely to be closed due to building damage hazards and safety.

\section{Importance of Transport Routes}

Different transport links and routes have different levels of importance or priority from a resilience perspective. It was necessary to understand the relative importance of the routes, and a methodology was developed [10] to assess the relative importance of the routes. This approach has been used to assess the importance of transport links in the Wellington region.

The relative importance of the routes in the transport network were assessed based on their network context, using a range of parameters listed in Table 1. The importance was characterised based on their use (traffic volumes, commercial and public transport), availability of alternative routes in the event of closure, and need for emergency services access (for example to hospitals, medical centres, fire stations, police stations and to access communities) and for access to repair other lifelines (for example water treatment plants, electricity substations, communication exchanges). 
Table 1: Factors used to assess the relative importance of transport links.

\begin{tabular}{|c|c|}
\hline Factor & Description \\
\hline $\begin{array}{l}\text { Emergency } \\
\text { Services }\end{array}$ & $\begin{array}{l}\text { Provides access to emergency services facilities, } \\
\text { eg hospitals. }\end{array}$ \\
\hline Lifelines & $\begin{array}{l}\text { Used to access other lifelines facilities, eg water } \\
\text { treatment plant. }\end{array}$ \\
\hline $\begin{array}{l}\text { Alternative } \\
\text { routes }\end{array}$ & $\begin{array}{l}\text { Availability of alternate routes to provide access } \\
\text { if this route was closed. }\end{array}$ \\
\hline $\begin{array}{l}\text { Traffic } \\
\text { volume }\end{array}$ & $\begin{array}{l}\text { Degree of disruption if route closed, depending } \\
\text { on usage. }\end{array}$ \\
\hline $\begin{array}{l}\text { Public } \\
\text { transport }\end{array}$ & $\begin{array}{l}\text { Used as public transport routes and hence socially } \\
\text { important. }\end{array}$ \\
\hline $\begin{array}{l}\text { Commercial } \\
\text { use }\end{array}$ & $\begin{array}{l}\text { Reliance by commercial - heavy vehicles, and } \\
\text { hence importance for economy. }\end{array}$ \\
\hline
\end{tabular}

These factors had been mapped spatially and combined using weightings for the different factors as part of the resilience studies for different Councils to assess their relative importance [3-6]. Weightings were developed through consultation with stakeholders in each local authority based on local factors of importance [3]. The state highways provided a spine through the different local road networks and therefore had a higher importance, except where there was a good secure alternative providing redundancy.

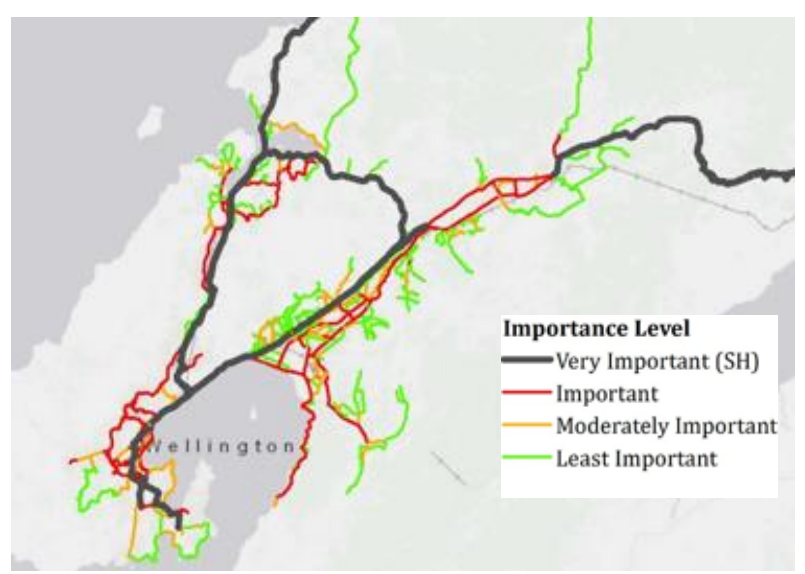

Figure 15: Relative importance of greater Wellington's transport routes (outer areas not shown for clarity).

The route importance maps that had been developed for the different local road networks were combined with the state highway network to develop an overall route importance map for the region. Part of this map is shown on Figure 15.

Some recent researchers have used the term "criticality" to describe the importance of different parts of an infrastructure network. The term "importance" or priority has been used since 2000 [10] in the assessment of resilience of transport networks in the Wellington region [3-6] and elsewhere [8].

\section{Criticality of Resilience Risks for Investment}

In the Wellington transport resilience study and programme business case, the term criticality has been used since 2016 to characterise the criticality of resilience risks in the context of the transport system (for prioritisation, action and investment). The criticality of the resilience risks affecting the transport routes was assessed as a combination of:

- Importance of the route to society, as represented by the relative importance of routes (Figure 15) and

- Severity of its resilience risks as represented by the disruption state (Figure 11).

Transport routes that are very important for the functionality of society which also have resilience risks that are extreme to catastrophic as represented by the disruption state will have the greatest criticality for prioritised consideration, action and investment.

The criticality of the resilience risks to the transport routes posed by each of the major hazards has been assessed using the disruption state associated with each hazard and the matrix shown in Figure 16. Given that the importance levels and disruption state had been mapped spatially using a GIS platform, the criticality was derived spatially using the same platform. This allowed the criticality to be derived efficiently using a geospatial combination of importance level and disruption state.

The criticality derived for the following natural hazards of importance in the Wellington region were compared, and the highest criticality from these different hazards was adopted:

- Earthquake

- Storms

- Tsunami

Also see Equation 1.

Criticality Score =

Highest of 〈Criticality in Earthquake|Tsunami|Storms〉

Importance Level of Transport Link

\begin{tabular}{|c|c|c|c|c|}
\hline & Least Important & Moderately Important & Important & Very Important \\
\hline None & Very low & Very low & Very low & Low \\
\hline Limited & Very low & Low & Low & Moderate \\
\hline Moderate & Very low & Low & Moderate & High \\
\hline High & Low & Moderate & High & Very high \\
\hline Severe & Low & High & Very High & Extreme \\
\hline Extreme & Moderate & High & Extreme & Extreme \\
\hline
\end{tabular}

Figure 16: Matrix used to derive criticality from importance of the transport link and its disruption state. 
In the Wellington transport resilience study, it was found that the combined criticality for earthquake and tsunamis for the transport system were higher than the criticality for storm events, as the impacts from earthquake and tsunami are higher.

The criticality rating derived using the matrix in Figure 16 ranged from 1 (where the disruption was very low and the transport link was least important) to 24 (where the disruption expected was extreme, that is closed for a long period of time, and the transport link was very important).

Study considered multi-modal transport, and this was explicit in the way the importance was derived considering public transport routes. Since the same level of resilience assessment had not been carried out for the railway system, the resilience of railway system was considered more subjectively using the known hazards in the Wellington region, and the potential impact on the railway [17-19], and observations of performance in past earthquakes in New Zealand (the 2016 Kaikōura earthquake) [21] and overseas [20]. Where the railway route adjoining the road transport link was also likely to be closed in a future event for a long period, the criticality score was adjusted as follows:

- Railway - the criticality score was increased by 5 (an approximately $20 \%$ increase in the criticality score).

The criticality represented an important metric used in the prioritisation of the resilience issues facing the Wellington region's transport network. In addressing the risk to transport resilience it was important to also consider other lifelines that are likely to be disrupted by the resilience risks along the same transport corridors. Therefore, the trunk bulk water, electricity and gas lifeline routes were considered, and where these routes share the road corridor and are also likely to be concurrently disrupted in the same hazard event, the following adjustments to the criticality score were made.

The scores adopted for the railway mode (20\%) and the other lifelines ( $4 \%$ to $12 \%$ ) were subjective and were agreed within the project team and shared and agreed with the stakeholders.

- Bulk water - score increased by 3 (approximately $12 \%$ )

- Electricity - score increased by 2 (approximately $8 \%$ )

- Gas - score increased by 1 (approximately $4 \%$ ).
The railway corridor, bulk water, trunk electricity and gas services were superimposed on the road transport corridors in GIS, and a combined criticality was derived using the above scores with the aid of the GIS platform used.

Through these measures, importance was given to take a multimodal and multi-utility approach in assessing the criticality of resilience risks. This multi-modal and multi-hazard approach meant that in prioritising resilience risks and thus investments to address these risks to transport resilience, a higher priority was afforded to addressing the resilience risks to transport links where the resilience of other modes and lifeline utilities are also likely to be improved at the same time, and this approach did influence the outcomes.

The criticalities along for the main transport corridor segments were considered and the highest criticality of that segment was chosen to represent the criticality for that transport segment or link. The corridor segments were taken as links between key intersections with other significant transport routes.

The prioritised resilience risks were classified based on the combined criticality (Figure 16) as:

- Extreme

- Very high

- High

- Moderate

- Low and

- Very low.

The corridor criticality allowed the resilience risks to be prioritised across the region including access to the Wellington Central Business District (CBD).

The resilience risks were grouped into the following sub-areas or connectivity for further consideration:

- Connection the region - routes that the important for connecting the different cities and districts together.

- Wellington CBD to International Airport - routes that provide connection between the $\mathrm{CBD}$ and the regional hospital and regional - international airport to the east.

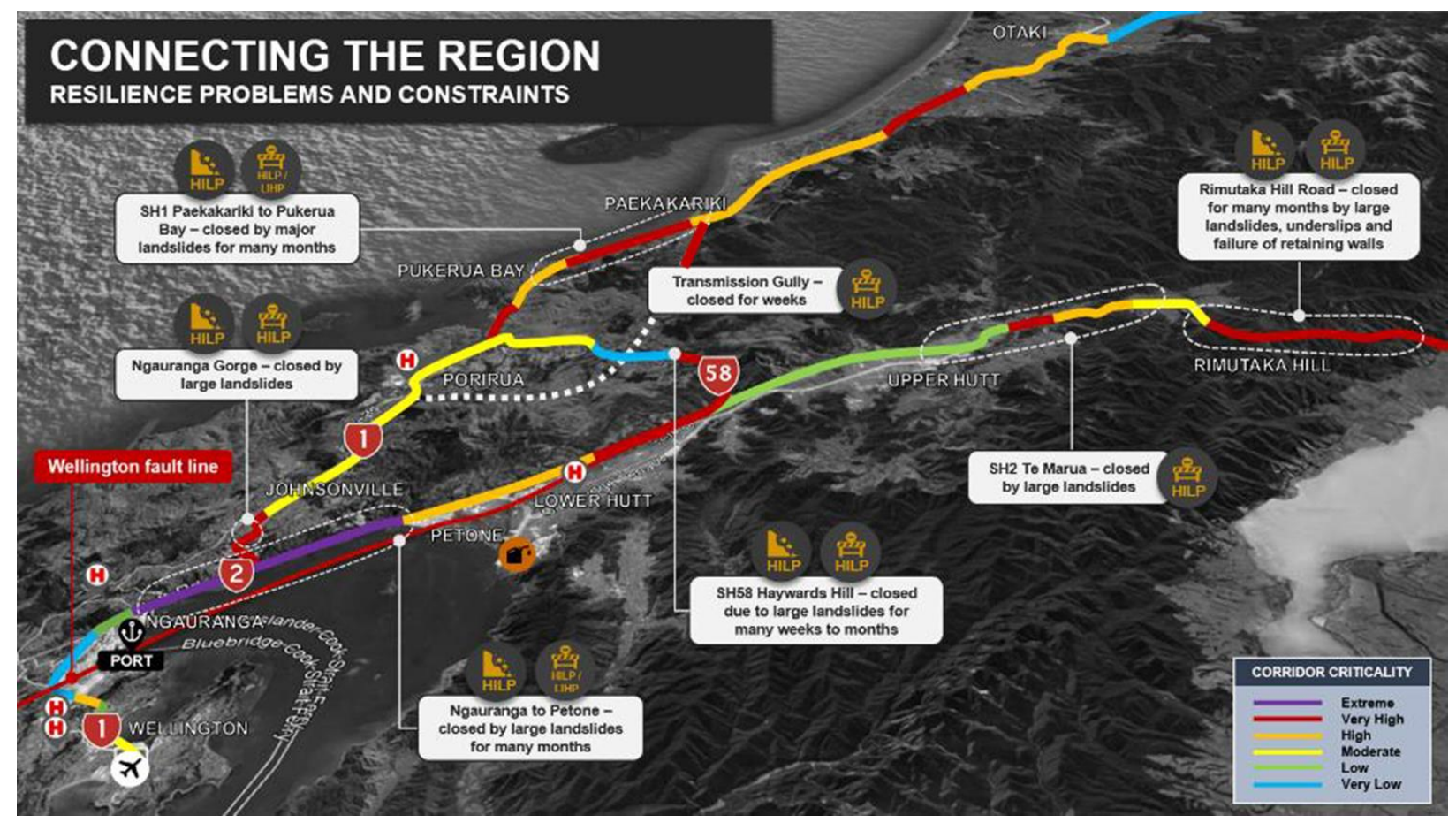

Figure 17: Combined corridor criticality map for greater Wellington (Wairarapa area to east excluded for clarity). 
- Wellington CBD to Johnsonville - routes that provide access to the north from the Wellington CBD.

- Connecting Porirua - routes that connect the communities across the Porirua district.

- Integrating Hutt Valley - routes that provide connectivity across the Hutt Valley sub-region.

- Connecting Wairarapa - routes that connect the Wairarapa communities together.

- Connecting Kapiti - routes that provides access between the communities across the Kapiti Coast district.

The prioritised resilience risks for the key routes connecting the region using the combined corridor criticality map for the Wellington region is shown in Figure 17. The Wairarapa area to the east is omitted in this map for clarity. Similar maps were developed at district or sub-district level.

\section{Functionality in a Range of Events}

It is important that the transport system provides access in a range of levels of hazard events. Societal resilience needs in different levels of hazard events differ. Three levels of events can be considered:

1. Routine operational level - the need is for socio-economic functionality and minimum disruption and rapid restoration of accessibility after small incidents.

2. Low Impact High Probability events - In more frequent and low impact events such as modest storm events, society will be almost fully functional, and the need would be to continue to provide near full capacity access for society to facilitate socio-economic functionality or rapid return to full functionality. The need in these low impact high probability (LIHP) events will be for resilience initiatives that provide near full capacity access.

3. High Impact Low Probability events - In contrast in infrequent large hazard events such as the 2010-2011 Canterbury earthquake sequence or the 2016 Kaikōura earthquake, the socio-economy will be severely restricted while society recovers, and the imminent need will be for access that enables emergency response and recovery to functionality. In this case full capacity functionality is not the need of the time, but limited access for recovery. Therefore, the resilience initiatives would need to focus on providing access for emergency response in the immediate aftermath in such High impact Low probability (HILP) events, followed by a reliable return to functionality to facilitate recovery.

Figure 17 also indicates which of the routes of higher criticality are likely to be affected in both LIHP and HILP events.

\section{Critical Resilience Risks in the Region}

Figure 17 shows that the major routes in and out of the region and between the cities in the region (Wellington, Lower Hutt, Upper Hutt and Porirua) have very high to extreme criticality resilience risks. The region will be isolated from the rest of New Zealand and the cities isolated between each other for long periods of time following a large local earthquake event, due to the closure of important land transport routes.

The Petone to Ngauranga section of State Highway 2 between Wellington and the Hutt Valley, and the Ngauranga interchange area, including the State Highway 1 and 2 interchange and the adjacent railway crossings were identified as extreme criticality - the highest level of resilience risks. It is noted that these risks also affect the adjacent railway and other key utilities that share the corridor, which contribute to these being the highest resilience risks.
These are followed by very high and high criticality resilience risks along sections of State Highways 1,2 and 58 and key local arterial roads, see Figure 17. Other sections of the highways and local arterial routes were identified as moderate criticality risks.

The transport network needs to be considered holistically as the lower criticality routes can provide important alternate routes for emergency access and recovery where the higher criticality routes are closed for longer periods and are difficult to restore. The prioritised resilience risk maps provided a very useful basis for the development of resilience enhancement initiatives and programmes for action on a holistic network basis.

\section{Stakeholder Consultation}

The resilience initiatives need to be actioned by multiple agencies across the Transport Agency, local authorities and KiwiRail. Also, the initiatives need to cater for the emergency response needs of society. The transport and local authorities, KiwiRail and the Ministry of Civil Defence and Emergency Management (now known as the National Emergency Management Authority) were included in the stakeholder consultation. The resilience study and the programme business case were developed from the beginning in consultation with the stakeholders. Obtaining their buy-in to the programme was therefore able to be achieved.

The Wellington Lifelines Group (WeLG) was included in the stakeholder consultation as they were developing a multi-utility resilience business case concurrently. WeLG was kept up to date on the results from this transport resilience study and business case, so that they could take on board the outcomes from this study in their own business case.

Several meetings to consult with each of the key stakeholders or local groups of stakeholders, as well as workshops with the wider group were held to agree the objectives, discuss resilience enhancement initiatives as they were developed, and to share the results of the study at each stage.

The stakeholder consultation included:

- Workshop with stakeholders to develop and agree the purpose of the transport resilience study and objectives (Figure 3).

- Individual meetings with each of the stakeholders, to share the resilience assessments and test these against their local knowledge and resilience concerns. This was facilitated by the fact that the 2012 Opus regional integrated transport resilience study [6] included the local authority asset owners and there was a good common understanding of the resilience issues across their areas and the region.

- Workshop with stakeholders to agree the resilience assessments, importance (Figure 15) and the criticality assessment (Figure 17).

- Presentation and obtain buy-in from the Regional Transport Committee, comprising road controlling authority representatives at executive leadership level.

\section{Stages 2 and 3 of Resilience Study}

An analysis to assess remaining risks was carried out as part of Stage 2 to take into consideration the resilience risks that will be addressed by transport projects that were already underway, and thus determine the critical resilience risks that will remain. This was followed by the development of interventions to address the resilience risks and a long-term programme of resilience interventions. These subsequent stages ( 2 and 3$)$ are not included in this paper. 


\section{DISCUSSION}

The resilience risks across the integrated transport system comprising the state highways managed by the New Zealand Transport Agency (NZTA) (also now known as Waka Kotahi) and eight local authorities across the Wellington region were able to be assessed in an integrated manner using a GIS platform. The GIS platform facilitated the entire network of state highways and principal, arterial and collector local roads to be assessed, whereas overseas studies have focussed on critical nodes such as bridges and tunnels only. Fundamental to the assessment of the resilience risks were the use of the resilience metrics of availability and outage states (Figures 4 and 5) that had been developed [9], which were meaningful metrics representing the functionality of the system (as opposed to only damage) that is important to society. These metrics were also able to be understood, related to and used by stakeholders. The derivation of a disruption state enabled the combination of the availability and outage states, as a single metric specifically for analyses purposes.

The importance of the links in the transport networks were prioritised based on an assessment based on their function, usage and need for emergency services and recovery of other lifeline facilities, based on criteria and weighting agreed with the stakeholders.

Criticality of the resilience risks derived as a combination of the importance (representing priority) and disruption (representing the resilience risks) enabled the resilience risks to be compared at system level, to enable prioritisation of resilience risks for investment. The criticality assessment also took a multi-modal and multi-utility approach, considering the concurrent impacts on the railway corridor and bulk water, trunk electricity and gas utilities that are also likely to be affected together with the road corridor, and are important for the functionality of society.

The inclusion of access for the recovery of other lifeline utilities in the assessment of importance, and the consideration of concurrent damage to other major lifeline utilities in the assessment of criticality is a significant step forward in taking a multi-utility lifelines approach.

This integrated assessment of criticality provided a strong basis for development and prioritisation of resilience investments to enhance the resilience of the transport network during subsequent stages of the project.

\section{CONCLUSIONS}

Wellington region has significant resilience risks from a range of natural hazards including earthquakes, tsunami and storms. A systematic approach enabled these risks to be assessed using the resilience metrics of availability and outage and mapped across all land transport networks, regardless of the managing authority. Characterising the importance of routes and their resilience risks enabled the criticality of the resilience issues to be assessed and therefore enabled the development of a register of prioritised resilience risks based on criticality.

The Petone to Ngauranga section of State Highway 2 between Wellington and the Hutt Valley, and the Ngauranga interchange area, including the State Highway 1 and 2 interchange and the adjacent railway crossings were identified as extreme criticality - the highest level of resilience risks. The presence of the adjacent railway and other key utilities that share the corridor, contributed to these being the highest resilience risks in the region, demonstrating the importance of multi-modal and multi-lifeline utility assessment. The very high and high criticality resilience risks were along sections of State Highways 1, 2 and 58 and key local arterial roads in the region.

This foundation enabled the complex multi-dimensional resilience issues to be considered across different levels of hazards for the whole transport system rather than for individual nodes or links. This approach was fundamental for the development of a prioritised programme of resilience enhancement measures during subsequent stages of the study, with the buy in of stakeholders.

This pioneering integrated study of transport resilience provides a framework that can be adapted and used by other transport authorities in New Zealand as well as in other countries.

\section{ACKNOWLEDGEMENTS}

The author acknowledges the permission from the Waka Kotahi NZ Transport Agency to publish this paper. The contribution of colleagues from Opus (now WSP) and the road controlling authorities and stakeholders including the NZTA, Greater Wellington Regional Council, territorial local authorities Wellington, Hutt, Upper Hutt, Porirua City Councils and the Kapiti Coast, Masterton, Carterton, Grey and South Wairarapa District Councils, KiwiRail and the Ministry of Civil Defence Emergency Management and local emergency management is gratefully acknowledged.

\section{REFERENCES}

1 CAE (1991). "Lifelines in Engineering - Wellington Case Study". Centre for Advanced Engineering (CAE), University of Canterbury, Christchurch, NZ.

2 Brabhaharan P (2004). "Systematic management of the risks to transportation networks from natural hazards". 2nd International Symposium on Transportation Network Reliability, 20-24 August, Christchurch, NZ.

3 Hodgkinson E and Brabhaharan P (2009). "Hutt Valley Road Network Risk Management Study". Report No GER 2009/20, Parts 1 and 2. Opus International Consultants, Wellington, NZ.

4 Mason D and Brabhaharan P (2015). "Resilience of road transportation lifelines for Porirua District". Institute of Public Works Engineers Australasia Conference, May, Rotorua, NZ.

5 Brabhaharan P (2010). "State Highway Resilience Study, Wellington Region". Opus International Consultants Limited, Wellington, NZ.

6 Brabhaharan P and Mason D (2012). "Wellington Region Road Network Earthquake Resilience Study”. Report No GER 2012-21, Opus International Consultants, Wellington, NZ.

7 CAE (1997). "Risks and Realities: A Multi-disciplinary Approach to the Vulnerability of Lifelines to Natural Hazards, based on the Work of the Christchurch Engineering Lifelines Group". Centre for Advanced Engineering (CAE), University of Canterbury, Christchurch, NZ, 312pp.

8 Speed J and Brabhaharan P (2006). "Western Bay of Plenty road network risk assessment". New Zealand Geotechnical Society 2006 Symposium on Earthquakes and Urban Development, 17-18 February, Nelson, New Zealand.

9 Brabhaharan P (2002). "Natural hazard risk management for road networks: Strategies for implementation". Ingenium - Annual Conference 2002. 14-16 June, Queenstown, NZ.

10 Brabhaharan P, Fleming MJ and Lynch R (2001). "Natural Hazard Risk Management for Road Networks. Part I: Risk Management Strategies". Transfund NZ Research Report 217, Opus International Consultants, Wellington, NZ, $75 \mathrm{pp}$.

11 Brabhaharan P and Moynihan S (2002). "Natural Hazard Risk Management for Road Networks. Part II: Implementation Strategies". Transfund New Zealand Research Report 212, Opus International Consultants, Wellington, NZ, 75pp. 
12 Brabhaharan P, Wiles LM and Frietag S (2006). "Natural Hazard Road Risk Management Part III: Performance Criteria”. Land Transport New Zealand Research Report 296, Opus International Consultants, Wellington, NZ, $117 \mathrm{pp}$.

13 Brabhaharan P (2006). "Recent advances in improving the resilience of road networks". Remembering Napier 1931 Building on 75 Years of Earthquake Engineering in New Zealand. Annual Conference of the New Zealand Society for Earthquake Engineering. 10-12 March, Napier, NZ.

14 Arumugam S and Brabhaharan P (2016). "Seismic and safety performance assessment and strengthening of tunnels in Wellington". New Zealand Society for Earthquake Engineering Annual Conference, 1-3 April, Christchurch, NZ.

15 Mason D and Brabhaharan P (2013). "Resilience of transportation lifelines in the greater Wellington area". 19th New Zealand Geotechnical Society Symposium, November, Queenstown, NZ.

16 NZTA (2016). "Strategic Case for Resilience Wellington". New Zealand Transport Agency (NZTA), Wellington, NZ.
17 Wellington Regional Council (1995). "Seismic Hazard Map Series: Slope Failure Hazard Maps”. Compiled from Works Consultancy Services Reports, Wellington, NZ.

18 Brabhaharan P, Jennings DN and McMinn JA (1993). "Liquefaction Hazard Study, Wellington Region". Works Consultancy Services, Wellington, NZ.

19 Brabhaharan P (1994). "Assessment and mapping of earthquake induced liquefaction hazards in the Wellington Region, New Zealand". First ANZ Young Geotechnical Professionals Conference, February 9-12, Sydney, Australia.

20 Yu J, Yong P, Reid S, Brabhaharan P and Meng P (2009). "The Ms 8.0 Wenchuan earthquake of 12 May 2008 reconnaissance report". Bulletin of the New Zealand Society for Earthquake Engineering, 43(1): 41-83. https://doi.org/10.5459/bnzsee.43.1.41-83

21 Mason D and Brabhaharan P (2019). "Resilience of transport corridors in the 2016 Kaikoura earthquake, to inform recovery and future slope design and landslide hazard management". Second International Conference on Natural Hazards \& Infrastructure, 23-26 June, Chania, Greece. 9pp.

\section{APPENDIX}

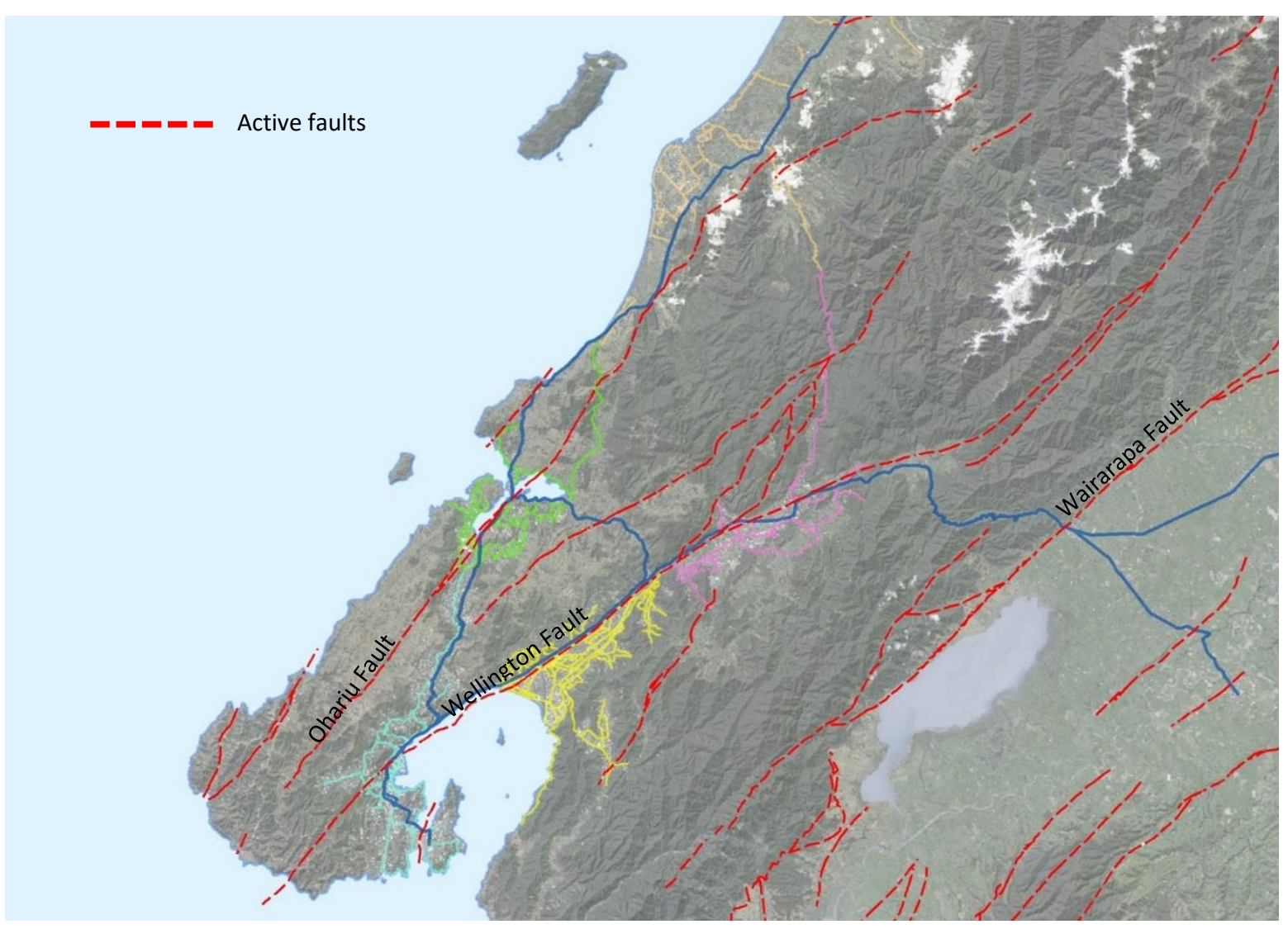

Figure A1: Active faults in the Wellington region. 